\title{
The Impact of Open Book Management on Achieving Differentiation in the Business Organization
}

\author{
Hamzeh Al- Sha'ar \\ Al-Balqa Applied University, Dept. of Business Administration \\ E-mail: hamzeh.alshaar@yahoo.com
}

Received: May 05, 2016 Accepted: May 18, 2016 Published: June 02, 2016

doi:10.5296/ijhrs.v6i2.9546 URL: http://dx.doi.org/10.5296/ijhrs.v6i2.9546

\begin{abstract}
This study aimed to know the concept open Book management and differentiation in the organizations and studying the effect of the relation between open book administration and differentiation in the organization. Study population consisted of all the commercial banks in Jordan, while the study sample consisted of (30) mangers and division mangers in Cairo Amman Bank and the Kuwait National Bank. The questionnaire has been used as an instrument to collect the study data. The study reached a set of results including: there are roles with statistically significance at significance level $(a \leq 0.05)$ for paying the wages and the incentives on achieving differentiation in the business organizations. There are differences open book management on differentiation in the organizations attribute to gender, scientific qualification and practical experience variables.
\end{abstract}

Keywords: Open Book Management, Differentiation in The organizations. 


\section{Introduction}

Open book management considers one the relatively new administrative methods, it is a simple method in its requirements deep in its effects, some call it "management by common vision "which is the management in which the interest is in the means and the goals in a comprehensive way, since the establishment's vision transforms to the mind and the conscious of those in charge of its message at their different administrative levels. Within this administrative method the strategic goals are clear to everyone. The role and the instrument to reach these goals divided, the energies launch and give the freedoms to all employees in the establishment to work to reach the desired superior goal (Al- harahsheh, 2006). Open Book management works to find common vision between all the workers, and enables everyone the freedom to experiment and explore the new, and releasing the employees who execute the works from the fear from error or failure, so their energies release their creative energies and innovative capabilities, here resides the important of Open Book management since it helps in formulating the relative climate for innovation which forms the vocabulary of the future language ( Al- Mekhlaphi, 2008).

Today organizations faces great challenges imposed on them to live a dynamic state in keeping up with the continuous forces, developments and changes in the internal and external work's environment. This environment with its different consequences made the organizations unable to work without knowing the opportunities and the threats to its external environment, such as the economic, cultural, social, political, legal, natural environment and the technology forces, also without knowing the strengths and weaknesses related to the internal variables such as the organizational learning, organizational differentiation, cultural and, organizational behavioral, the issues that determine the extent of the organizations benefit from the opportunities and encountering surrounding threats (Bostan\&Taha, 2009).

\subsection{Study Problem}

Researchers have noticed that the need requires studying the importance of disseminating differentiation through depending on the Open Book management, so the main of this study is to find the impact of Open Book management on achieving differentiation. However, the purpose of this study is to answer the following questions:

1- What is the effect of open Book management on the differentiation in the organizations?

2- Is there a correlation between the Open Book management and differentiation in the organizations attribute to the demographic variables?

\section{Methodology}

Descriptive analytical method is used through designing the study questionnaire for data collection and analysis to extract the results. Target population consists of the commercial banks operating in the Hashemite Kingdom of Jordan (22) banks. Researcher selected the upper and middle management level to build the study sample. Two commercial banks were selected by the purposive method because of ease of dealing with them. (30) Managers and head of division were selected from the two banks, (15) individuals from each bank. To 


\section{Macrothink}

International Journal of Human Resource Studies

ISSN 2162-3058 2016, Vol. 6, No. 2

achieve the study goal, the questionnaire will be used as the measurement instrument. Frequencies and Percentages to know the characteristics of the study sample participant. Means, and standard deviations to analyses the study sample answer to the items of Open Book Management.

\subsection{Study Model}

Independent Variable:

Open Book Management

- Information sharing

- Teaching all of the employees

- Empowering the employee

- Paying the employees
Dependent Variable

Achieving differentiation in the businesses organizations

\subsection{Study Hypotheses}

This study attempted to test following hypotheses.

Ho1: There is no statistically significant impact at significance level $(\alpha \geq 0.05)$ of the open book management (knowledge sharing, teaching the employees, employees empowerment, paying the salaries and incentive) on achieving differentiation in the businesses organization.

Ho2: There is no statistically significant impact of open book management (information sharing, employees teaching, employee's empowerment, paying the salaries and the incentives) on achieving differentiation in the business organizations due to the personal and occupational variables.

\subsection{Study Goals}

This study aims to:

1- To know the concept open book management and differentiation in the organization.

2- Studying the impact of the open book management and differentiation in the organization. 


\subsection{Operational Definitions}

\section{S.T.B.P}

\begin{tabular}{|l|l|l|}
\hline $\begin{array}{l}\text { Sharing the financial indexes information especially the stock } \\
\text { price. }\end{array}$ & Share & S \\
\hline $\begin{array}{l}\text { Teaching all of the employees how to read and understand the } \\
\text { financial indexes variables and the reports related to the costs. }\end{array}$ & Teach & $\mathrm{T}$ \\
\hline $\begin{array}{l}\text { Employee's empowerment to make the necessary change } \\
\text { (teaching, training, qualifying and authority delegation). }\end{array}$ & Empowerment & E \\
\hline $\begin{array}{l}\text { Paying the employees fair wages and salaries and share of } \\
\text { revenues and incentives in the form shares to the employees }\end{array}$ & Pay & $\mathrm{P}$ \\
\hline
\end{tabular}

\subsection{Theoretical Framework}

\subsubsection{Open Book Management}

Open Book management have appeared, which means the clarity of the legislations, ease of understating them, their stability and harmony with each other, it's clear language, its objectivity, flexibility and development according to the economic, social and administrative changes to correspond with the era spirit in addition to facilitating the procedures, information dissemination, disclosing them and ease of access to them to be available for all ( Harb, 2011).

\subsubsection{Significance of the Open Book Management}

Open Book management consider as code of conduct creating trust in the others, significance of the open Book Management can be illustrated through the following:

- Transparency works for participation in decision making allowing the citizens awareness and informing them about the available options.

- The Organization becomes for from ambiguity in its orientations which increases belongings sprit to it.

- Enhancing self- monitoring in the organization transparency promises more secure life to the employees through the states bodies monitoring over all elements that might cause any kind of risks, and encourages the best utilization of the organization assets ( Yaseen, 2007, P.125).

\subsubsection{Open Book Management Requirements}

There are many requirements should be focused on to enhance the Open Book Management in the institutional work that should be available to guarantee its application ( AL- thaher, 2009, P.10) 
1- Necessity for the presence of practical mean, not the presence of obsolete legal text to be an instrument of the mangers hands to provide specific procedures to check the institutions performing their functions, and to know the shortages.

2- Enhancing accountability value at the different managerial levels, and making the procedures to enhance this value.

3- Dealing with occupational turnover policy

4- Preparing healthy work environment based on three pillars: employees satisfaction, objective follow- up, group sprit dissemination.

5- Facilitating the works procedures in a way to allow performing activities without complexity.

6- Necessity for organizing qualification courses for the employees

7- Leadership requires transparency, adopting the openness and clarity mode by the manger in dealing with the others, by sharing the needed information.

\subsection{Organizational Differentiation}

Differentiation concept is the ability to offer service in an innovative different way than others offering.

In order to achieve differentiation there should be change and review the existing culture to make sure it is in accordance with this differentiation, also there is the need for developing differentiation culture in the organization (Ab'as, 2004).

It is a set of thinking, behaving and dealing ways of the employees in the organization with each other's from one side, and with the customers, suppliers and shareholder's on the other side, since it covers most of the organization's relations with the local society.

This culture of a group of values, goals and systems that support differentiation. For this concern, there should be available a methodology to achieve the institutional differentiation according to a frame which consists of eight elements and activating this frame through assuring the existence of the elements, which are the path ( orientation, operations, structure, leadership, culture, exchange of information, decisions, and performance management ( Eed\&Hosam, 2004, P.9).

\subsection{Competitive Advantage}

In studying competitive advantage there are a set of frames that have emerged, but the newest frame in the one which depends on the resource, and that competitive advantage is among the most important assets in the organization. ( Roaf, 2009).

(Almograbi, 2000), has identified competitive advantage as the term that indicates at fields the organization is able to compete others through a more effective way, to be a strength in its productivity, marking or financing activities. Competitive advantage depends on the results of testing, and analyzing all the internal strengths and weaknesses, in addition to 
opportunities and threats surrounding the organization's environment comparing to its competitors in the market.

They are four elements should be taking care about them, and they are necessary to establish competitive advantage.

1- Organization's Strategic content

2- Internal factors, such the quality of the human resources financial, infrastructure, productivity capabilities and administrative resources.

3- Supporting industrial that basically depend on the suppliers.

4- Customer's needs: all if the elements should interact to achieve customers' needs which intern leads to achieving competitive advantage.

\section{Literature Review}

(Abo Hatlah, 2012) study "Effect of the organizational policies on occupational empowerment of the employees at the governmental departments in Tabyok region in kingdom of Saudi Arabia "this study aimed to know the effect of the organizational policies on occupational empowerment of the employees. To achieve the study goals, a developed questionnaire has been used to collect tada from the sample individuals, (730) participants, (590) questionnaires were retrieved. (SPSS) program used to analyze the collected data. This study reached that the degree of available organizational policies for the employees \& empowerment level was high, and the presence of effect of the organizational policies (goals, organizational support, work relations, incentives, promotion, and performance evaluation) on occupational empowerment level.

(Al- Salem, 2011) study "Effect of the administrative empowerment on the occupational performance in passports department Jad'ah Governorate".

To achieve its goal, the researcher used the descriptive analytical method and the field method, the study was divided into theoretical and field parts. To identify the administrative empowerment and its basic components (Knowledge, skills communication, information flow, organizational trust, incentives, organizational culture, participation and giving authority), then the occupational performance concept. In the field part, researcher used the questionnaires as an instrument to collect data from the respondents from simple random sample (312) respondents, and used a number of statistical methods. Frequencies, percentages, means, Chi- square to test the hypotheses validity.

The study reached a number of results, the most important that the administrative empowerment represents in its elements influencing the occupational performance. And recommending the necessity to pay attention to the issue administrative empowerment, since it contributes to solving some problems relating to the occupational performance.

(Tseng, 2010) study “ The Effect of learning organization practices on organizational commitment and effectiveness for small and medium- sized enterprises in Taiwan” 


\section{Macrothink}

This study aimed to reveal the effects of the learning organization practices on the organizational commitment and effectiveness in the small - midsized enterprises in Taiwan. The researcher used the quantitative research by distributing (300) questionnaires. The study found that the learning organization has strong and positive relation with the organizational effectiveness, also the relation between organizational commitment and organizational effectiveness is a mutual relation but not equal, since organizational commitments has positive influence on organizational effectiveness, while organizational effectiveness has weak influence on organizational commitment.

\section{Results of the Study}

\subsection{Hypotheses Testing}

Ho1a: There is no statistical significance at significance level $(a \leq 0.05)$ of information sharing in achieving differentiation in the businesses organization.

First sub-hypothesis:

Table (1)

\begin{tabular}{|l|l|l|l|}
\hline T- Calculated & T-Tabulated & Sig T & Result Ho \\
\hline 23.148 & 1.9842 & 0.000 & Rejection \\
\hline
\end{tabular}

One sample T-test is used, and found that $\mathrm{t}$ - calculated value $=23.148$ greater than its tabulated value, since the decision rule is : Accepting Ho if the calculated value less than the tabulated value, and rejecting Ho if the calculated value is greater than the tabulated value, so Ho is rejected and accepting Ha.

This means that there a significant impact at significance level $(a \leq 0.05)$ of information sharing in achieving differentiation in the businesses organizations.

Ho1b:

There is no significance impact at significance level $(a \leq 0.05)$ of teaching the employees in achieving differentiation in the business organizations.

Table (2)

\begin{tabular}{|l|l|l|l|}
\hline$\alpha \mathrm{F}$ & Mean square & $\mathrm{F}$ & Sig \\
\hline 2 & 0.76 & 0.68 & 0.53 \\
\hline
\end{tabular}

We see from the table that sig value reached 0.53, which is insignificant at significance level $(\mathrm{a}=0.05)$, this means rejecting (Ho) and accepting (HA) which means there is a significance impact at significance level $(\mathrm{a} \leq 0.05)$ of teaching the employees in achieving differentiation in the business organizations 
Ho1c:

There is statistical significance impact at significance level $(a \leq 0.05)$ of employees' empowerment in the business organizations.

Table (3)

\begin{tabular}{|l|l|l|l|}
\hline$\alpha \mathrm{F}$ & Mean square & $\mathrm{F}$ & Sig \\
\hline 1.4762 & 0.7382 & 1.1304 & 0.49 \\
\hline
\end{tabular}

We see from the table that sig value reached (0.49) which is insignificant at level $(a=0.05)$ this means rejecting (Ho) and accepting (HA) which means there is a statistical significance impact at significance level $(a \leq 0.05)$ of employee's empowerment in achieving differentiation in the businesses organization.

Ho1d:

There is no statistical significance impact at significance level $(a \leq 0.05)$ of paying wages and incentives in achieving differentiation in the business organizations.

Table (4)

\begin{tabular}{|l|l|l|l|}
\hline$\alpha \mathrm{F}$ & Mean square & $\mathrm{F}$ & Sig \\
\hline 1 & 0.002 & 0.002 & 0.96 \\
\hline
\end{tabular}

We see from the table that sig value reached (0.96) which is insignificant at level $(a=0.05)$, this means rejecting (Ho) and accepting (HA) which means there is a statistical significance impact at significance level $(a \leq 0.05)$ of paying the wages and incentives in achieving differentiation in the business organizations.

Ho2: There is no statistical significance impact at significance level $(a \leq 0.05)$ of Open Book Management (information sharing, teaching employees, empowering, paying the wages and incentives) in achieving differentiation in the business organizations due to the demographic and occupational variables.

Ho2a:

There is no statistical significance impact at significance level $(a \leq 0.05)$ of information sharing in achieving differentiation in the businesses organizations due to gender variable.

Table (5) 


\begin{tabular}{|l|l|l|l|}
\hline T- Calculated & T- Tabulated & Sig & Result of Ho \\
\hline 23.249 & 1.9842 & 0.000 & Rejection \\
\hline
\end{tabular}

One sample t-test is used, and found from the table what t-calculated value $=23.249$ greater than its tabulated value, so we reject Ho, and accept (HA), this means that there are differences with statistical significance of the influence of open book management on differentiation in the business organization attribute to gender variable.

Ho2b:

There is no statistical significance impact at significance level $(a \leq 0.05)$ of teaching the employees in achieving differentiation in the businesses organizations attribute to the scientific qualification.

Table (6)

\begin{tabular}{|l|l|l|l|}
\hline T- Calculated & T- Tabulated & Sig & Result of Ho \\
\hline 21.11 & 1.95 & 0.000 & Rejection \\
\hline
\end{tabular}

Results from the table above shows t- calculated is greater than t- tabulated, so rejecting Ho and accepting (HA), which means there are differences with statistical significance of the influence of open Book Management attribute to the practical experience.

\subsection{Study Results}

After analyzing the study data and testing its hypotheses the study reached the following:

- There is a statistical significance impact at significance level $(a \leq 0.05)$ of paying the wages and incentives in achieving differentiation in the business organization.

- There are difference with statistical significance of the influence of open Book management on differentiation in the business organizations due to gender, scientific qualification and practical experience variables.

\section{Recommendations}

Based on the results of the field study, researcher recommending the follow:

1. The work to disseminate administrative empowerment culture between the employees in the banks through enhancing the organizational values and tradition motivating this attitude.

2. Interest in developing and training the employees according to scientific programs with the goal to develop their capabilities and improving their performance level through:

- Conducting short- medium periods of training programs to train the 
employees.

- Encouraging the employees and continuously supporting them to learn in all fields relating to their work.

- The necessity to allow the application of the acquired skills from the training.

- Expanding in granting the authorities to the employees and engaging them in policies drawing and making the decisions relating to their work, either through work teams or committees, to raise their moral sprit, and to support the trust and cooperation climate, and natural cooperation will contribute to the success of open book management, by expanding training programs granting the authority, conducting workshops, with the focus on the importance of open book management and differentiation.

\section{References:}

Norman, Steven, Mark, Souwr (2010), The impact of positivity and Transparency on Trust in Leaders and their Perceived effectiveness, the Leadership Quarterly, Elsevier, Science Direct, United States, 350-3664.

Tseng, Chien- Chi (2010), The Effects of learning organization practices on organizational commitment and Effectiveness for small and medium -sized enterprises in Taiwan, A Dissertation Submitted to the Faculty of the Graduate School of the University of Minnesota.

Powel D. Jap (2001), Perspective on Joint Competitive Advantages in Buyer - Suppliers relationships, international Journal of research on Marketing.

Al-Mekhalfi, A. (2008). Leadership style of the public and private secondary schools principals in San'a City for the teacher's point of view and their relation with occupational satisfaction" unpublished master theses, Arab Amman University, AmmanJordan.

Al- Harahshe, M. (2006) the relationship between the leadership styles practiced by the school's principals and the level of the teacher's organizational commitment in ALTaleeleh governorates' schools. Journal of psychological education sciences, Volume, 7, N. 1, Faculty of education, AL-Bahrain university, kingdom of Bahrain. PP: 12-46.

Bostan, A \&Taha, H. (2009) Approach to the educational management, Kuwait- Dar AlQalam.

Abohatleh, Kh (2012). Effect of the organizational polices on the employees occupational empowerment working K.S.A - Dar Al- Ma'moon for publication and distribution.

AL- Salem, A (2011), Effect of the administrative empowerment on the occupational performance in passports department, Jadah Governorate, K.S.A, unpublished master theses, king Abdeelazeez University- K.S.A.

Harb, N (2011). Administrative Transparency Reality and its Application Requirements at 
the Palestinian universities in Gazza strip, unpublished master theses, Islamic University - Gazza.

Ab'as, S (2004). Innovative leadership and the unique performance training portfolio to develop the administrative excellence first education, Dar Wa'el for publication and distribution, Amman- Jordan.

Al- Mograbi, K (1995). Organizational behavior, concepts and basics of the individual and the group behavior in the organization, Dar Al- Fiker, AL - Arabia for Publication and Distribution , Amman- Jordan.

Ra'of, K (2009). Developing the organizational Culture of the governmental organizations in Algeria: Applied study by using Harison Stocks model, Research Submitted to the international conferences for the administrative development, held in Al- Riyad - April -2009..

Jaleel, M (2007). Measuring the Jordanian industrial companies, satisfaction with consultation services offices working in Jordan, unpublished mater thesis, Arab Amman University - Amman - Jordan.

Sahli, F (2009). Role of the organizational culture in activating the electronic management applications. Unpublished master thesis,Nayef Arab University for security sciences, Al - Riyad.

Eed, R \&Hosam , A (2004). Organizational culture and the creative climate at the educational institutions, Journal of the Arabic education future, AL - Mansoora university, Vol. 6, No 32, pp.: 9-57.

Thaher, N (2009). Knowledge management, First Edition, Jadara for Global Book for publication and distribution Amman- Jordan.

\section{Copyright Disclaimer}

Copyright for this article is retained by the author(s), with first publication rights granted to the journal.

This is an open-access article distributed under the terms and conditions of the Creative Commons Attribution license (http://creativecommons.org/licenses/by/3.0/). 